\title{
Risk Assessment for Ship Safety Development in Surabaya Western Access Channel
}

\author{
Bambang Siswoyo ${ }^{1, a, *}$, Arif Fadillah ${ }^{2, b}$, Putra Pratama ${ }^{1, c}$ and Rizky Irvana ${ }^{1, d}$ \\ ${ }^{1}$ Research and Development Agency for Transportation, Ministry of Transportation, Jakarta, \\ Indonesia \\ ${ }^{2}$ Department of Naval Architects, Darma Persada University, Jakarta, Indonesia \\ a.siswoyobambang71@gmail.com,b.arif_fadillah@ftk.unsada.ac.id,c. \\ putrapratama81@gmail.com andd.rizky4568@gmail.com \\ *corresponding author
}

Keywords: Formal Safety Assessment, Surabaya Western Access Channel, ship safety, risk assessment, Tanjung Perak Port

Abstract: Tanjung Perak Port is one of the main ports in Indonesia that serves the distribution of goods in eastern Indonesia, with increasing sea transport activities at the port. It is necessary for the shipping access channel to accommodate these activities. The Surabaya western access channel (APBS) has been done revitalization of course will be more vessels that will cross APBS, the number of ships that cross the access channel will certainly cause the risk of a cruise accident, for that need to be done review for mapping the risk of accidents in the Surabaya western access channel. The purpose of this study is to improve the safety of shipping by applying the risk of accidents in APBS by using Formal Safety Assessment (FSA) methodology. The results of the study show the causes of accidents before the revitalization is 40 cases of accidents while the accident that occurred after the revitalization is as many as 18 cases with the most causes of human factor. Increasing the safety of the shipping is necessary with increase the competence of human and law enforcement of shipping activities in the APBS.

\section{Introduction}

The shipping channel is one of the main facilities of a port and has an important role as an exit and entry to the port. The APBS is a channel to serve 17 Surabaya metropolitan ports. Port of Tanjung Perak in Surabaya is one of the main ports in Indonesia with the number of ship visits in 2016 reaching 12,499 units or 80.42 million GT which makes Tanjung Perak Port the second busiest port after Tanjung Priok in Jakarta. Quality of service in Tanjung Perak Port is of course very important as well as the safety factor of shipping in Tanjung Perak waters.

Sailing flow to the Port of Tanjung Perak there are two channel namely the Surabaya Western Access Channel (APBS) and Surabaya Eastern Access Channel (APTS). Before revitalization the western channel can be navigated by large vessels or by draft until 9.50 meters with wide is 100 meters, while the eastern channel is widely used small ships with draft up to 4 meters. Postrevitalization, APBS has a depth of up to minus 13.5 meters' width of 150 meters.

The length of APBS is about 24.2 miles or about $43.6 \mathrm{~km}$, with the problem of crossing of pipe line, cable, the undeveloped shipwreck and port basin. With the condition of the long cruise line and 
there are some obstacles above, it is very vulnerable to the occurrence of marine accidents either aground, ship collision, or other types of accidents, such as work accidents, fires and others that would negatively impact the voyage in APBS, further make an impact on the activities of the ship's entry into the port of Tanjung Perak

The largest vessel using APBS for bulk carriers is with Gross Tonnage 51,984 GT with LOA: 230 meters and draft: 14.6 meters. As for container ships with Gross Tonnage: 48,338 GT with Length (LOA): 255,36 meters and Draft: 10.4 meters. In general, the APBS is still safe to navigate the vessel, but according to the projection of ships visiting the APBS and it is estimated that in 2030 the water depth in APBS should be deepened again with a depth above 15 meters.

After the revitalization of the channel, ships more use the channel, the number of ships that cross the channel will certainly cause the risk of crash accident. Accidents that occur in the channel consists of 5 types of accidents namely collision, sink, grounding, fire and others. Before the channel revitalization the number of accidents occurring in the APBS from 2013 to 2014 as many as 43 cases whereas after the channel revitalization of the number of accidents from 2015 to 2016 is as many as 22 cases or decreased almost $100 \%$.

In this study, it is necessary to study for mapping of accident risk in the channel with use of Formal Safety Assessment (FSA) method. The results show that from the five types of accidents that occurred the highest risk is the ship collision followed by ship fire. If ships are monitored more cautiously and implemented of law enforcement, the risk of accidents can be reduced. In this case, any risk from the cause of accidents in the APBS can be reduced by $10-40 \%$ and the benefits of accident risk reduction can save expenses by $30-50 \%$.

\section{Methodology}

The Formal Safety Assessment (FSA) is a rational, structured and systematic methodology or process to assess risks associated with maritime activities and to evaluate the costs and benefits of multiple risk control options, with using risk analysis and cost benefit assessment (International Maritime Organization, 2002). The FSA aims to reduce existing risks, while improving marine safety, which includes life, health, marine environment and property rights. Figure 1 shows the FSA Method.

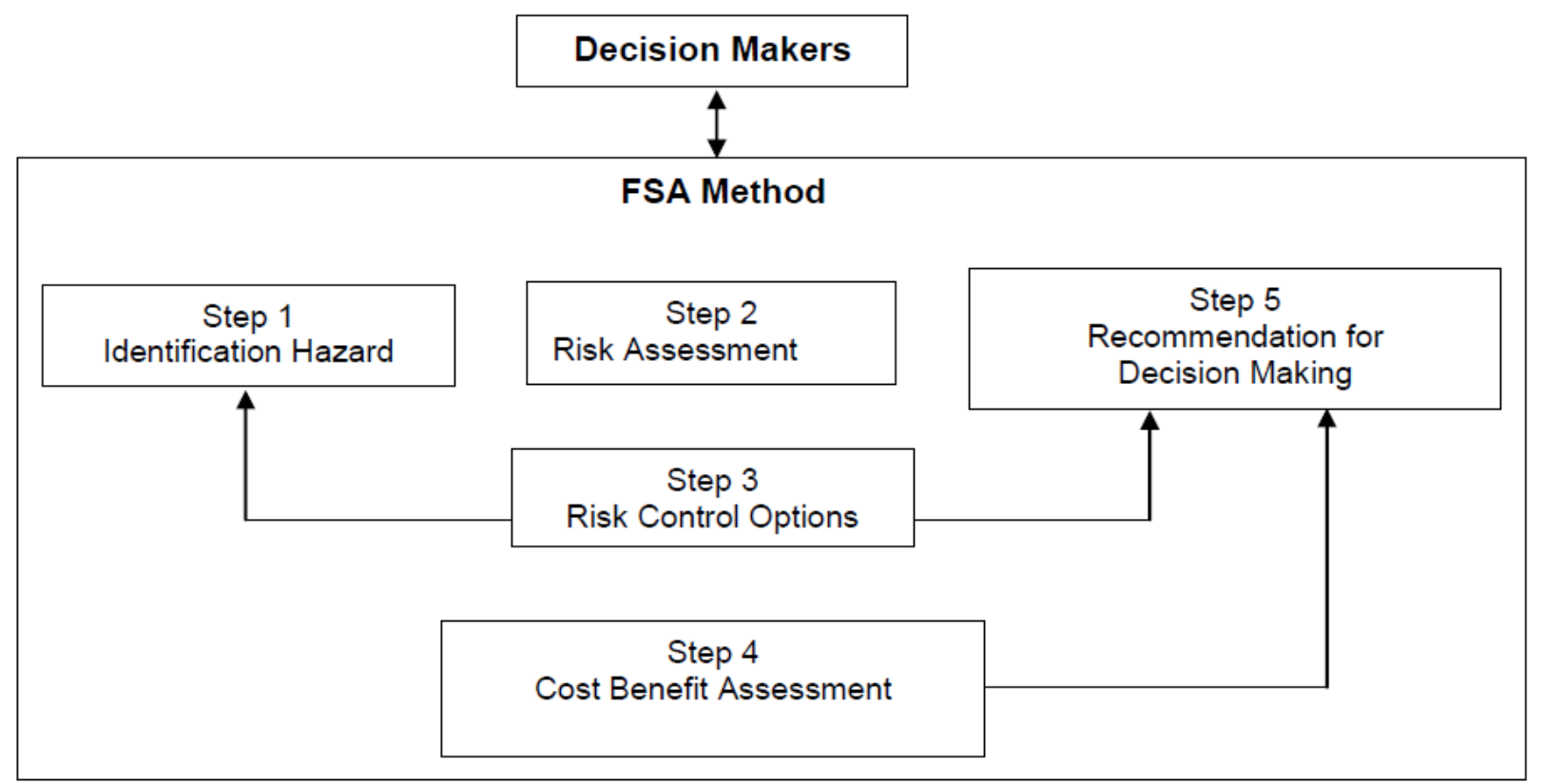

Figure 1: Formal Safety Method 


\subsection{Hazard Identification}

Hazard Identification is a list of all accident scenarios relevant to potential causes and their consequences, in response to the question "what error might occur (IMO, 2002).

\subsection{Risk Assessment}

These objectives can be achieved by using techniques that match the model of risk being made and attention focused on high-rated risk. The value in question is the level of risk, which can be differentiated into:

a. Risk that cannot be justified or accepted or intolerable.

b. Risks that do not need further precautions or negligible.

c. The risk that the level is between intolerable and negligible level.

\subsection{Risk Control Selection}

The purpose of step 3 is to propose effective and practical Risk Control Options (RCO), through the following four principle steps:

a. Focusing on risks that require control,

b. Identify actions to control potential risks (risk control measures $=\mathrm{RCMs}$ ).

c. Evaluate the effectiveness of RCMs in reducing risk

d. Group RCMs into practical options.

\subsection{Cost and Benefit Assessment}

The purpose of step 4 is to identify and compare the benefits and costs of implementing each RCOs identified in step 3. Costs must be expressed in life cycle costs, including initial, training, workshop, decommission, and others. Benefits may include reductions in fatalities, injuries, casualties, environmental harm and clean-up, and others. The equation used to solve this problem is with the Cost of Averting a Risk Index (ICAR) as given in the following equation:

Where:

$$
\frac{(\Delta C-\Delta B)}{\text { Risk Reduction }}
$$

$$
\begin{array}{ll}
\text { ICAR } & =\text { Implied cost of averting a risk } \\
\Delta \mathrm{C} & =\text { Cost of risk control } \\
\Delta \mathrm{B} & =\text { Economic benefits of the application of } \\
& \text { risk control } \\
\text { Risk Reduction } & =\text { Decrease in risk after control }
\end{array}
$$

\subsection{Recommendations for Decision Making}

The aim of step 5 is to emphasize recommendations to be made to decision-makers, in a way that can be audited and traceable.

\section{Result and Discussions}

In hazard identification the first objective can be accomplished by creative combinations and analysis aimed at identifying all relevant hazards. In this process, the main goal is to find the causes and effects of accidents and hazards. The next goal is to group these elements into concreteness. In addition, the 
level of consciousness affects each factor. The set of data related to marine accidents to quantitative values and the amount of output obtained as a list of hazards and scenarios related to the level and description of cause and effect. In this case, 5 hazards identified in APBS over the 6-year period from 2010 to 2016, including collision, fire, sink, grounding and other events that can be life-threatening and property and the factors of the cause of the accident are categorized into 3 namely human, technical, and nature.

Evaluation of risk assessment is an important factor of the FSA's methodology. For the development of an integrated security system, the total number of risk should be known. The FSA Methodology will figure out the information and accident details and provides quantitative risk estimates.

Table 1: Severity Index

\begin{tabular}{|c|c|c|c|}
\hline SI & Severity & Human & Ship \\
\hline 1 & Minor & minor injuries & Local equipment damage \\
\hline 2 & Significant & severe injuries & Non-severe ship damage \\
\hline 3 & Severe & multiple severe injuries & Severe damage \\
\hline 4 & Catastrophic & Multiple fatalities & Total loss \\
\hline
\end{tabular}

IMO 2002 (GUIDELINES FOR FORMAL SAFETY ASSESSMENT (FSA))

From the standpoint of risk assessment, the system-dangerous (or event) circumstances must be identified and indicated in the risk model. For this subject, total risk must be determined quantitatively. However, the risk is explained by the frequency of an event that causes its damage and severity. If an event has a low frequency, the risk may be considered low, despite its high severity. Therefore, the total risk is the number of probabilities of occurrences in which the danger occurs. Risk can be characterized by SI function (Severity) and possibly (F). Table 1 shows the level of severity index for human and ship.

Meanwhile Table 2 shows the frequency index of ship accidents that can occur. If the frequency is small, then a particular place or area is rarely hit by an accident, but if the frequency is high this place has many accidents.

Table 2: Frequency Index

\begin{tabular}{|c|c|l|}
\hline Fi & Frequency & \multicolumn{1}{c|}{ Definition } \\
\hline 7 & Frequent & Likely to occur once per month on one ship \\
\hline 5 & Reasonably probable & Likely to occur once per year in a fleet of 10 ships \\
\hline 3 & Remote & Likely to occur once per year in a fleet of 1000 ships \\
\hline 1 & Extreme remote & $\begin{array}{l}\text { Likely to occur once in the lifetime (20 years) of a world fleet } \\
\text { of 5000 ships. }\end{array}$ \\
\hline
\end{tabular}

IMO 2002 (GUIDELINES FOR FORMAL SAFETY ASSESSMENT (FSA))

Table 3 shows the risk index, which is a mix of severity and frequency index. The table explains how much danger should be addressed. If the green area the accident can be ignored, if the yellow area should be responded and if in the red area it must immediately provide action. 
Table 3: Risk Index

\begin{tabular}{|c|c|c|c|c|c|c|c|c|}
\hline & 4 & 5 & 6 & 7 & 8 & 9 & 10 & 11 \\
\cline { 2 - 10 } Severity & 3 & 4 & 5 & 6 & 7 & 8 & 9 & 10 \\
\cline { 2 - 11 } & 2 & 3 & 4 & 5 & 6 & 7 & 8 & 9 \\
\cline { 2 - 11 } & 1 & 2 & 3 & 4 & 5 & 6 & 7 & 8 \\
\hline
\end{tabular}

Table 4 illustrated data the number of ships that pass through the APBS from year 2010 to year 2016. At the beginning of the data collection, one of the required is how much the number of ship traffic passing through the Western Sailing Channel to the port.

Table 4: Ship Traffic at Surabaya Western Access Channel

\begin{tabular}{|c|c|c|c|}
\hline No & Year & Unit & GT \\
\hline 1 & 2010 & 14,197 & - \\
\hline 2 & 2011 & 14,117 & $72,730,588$ \\
\hline 3 & 2012 & 14,773 & $73,122,180$ \\
\hline 4 & 2013 & 14,198 & $76,293,701$ \\
\hline 5 & 2014 & 14,039 & $75,559,177$ \\
\hline 6 & 2015 & 13,452 & $77,000,000$ \\
\hline 7 & 2016 & 12,499 & $80,415,334$ \\
\hline
\end{tabular}

After knowing the general description of the condition of Surabaya's western access channel, then the most important thing is to present the accident data that ever happened. Table 5 and 6 shows the accident data occurring in the APBS from 2010 to 2016. 
Table 5: Ship Accident at Surabaya Western Access Channel

\begin{tabular}{|c|c|c|c|c|c|c|c|}
\hline No & Year & Collusion & Sink & Grounding & Fire & Other & Total \\
\hline 1 & 2010 & 14 & 0 & 3 & 1 & 9 & 27 \\
\hline 2 & 2011 & 5 & 2 & 1 & 8 & 6 & 22 \\
\hline 3 & 2012 & 1 & 2 & 1 & 4 & 0 & 8 \\
\hline 4 & 2013 & 14 & 2 & 1 & 4 & 0 & 21 \\
\hline
\end{tabular}

SURABAYA PORT AUTHORITY

Table 6: Ship Accident at Surabaya Western Access Channel

\begin{tabular}{|c|c|c|c|c|c|c|c|}
\hline No & Year & Collusion & Sink & Grounding & Fire & Other & Total \\
\hline 5 & 2014 & 14 & 2 & 2 & 3 & 1 & 22 \\
\hline 6 & 2015 & 5 & 1 & 1 & 4 & 1 & 12 \\
\hline 7 & 2016 & 3 & 2 & 2 & 3 & 0 & 10 \\
\hline \multicolumn{2}{|c|}{ Total } & 56 & 11 & 11 & 27 & 17 & 122 \\
\hline
\end{tabular}

SURABAYA PORT AUTHORITY

This data is needed to analyze the patterns and types of accidents occurring in the West Surabaya Sailing Channel which will then be included in the form of frequency criteria. In APBS, the types of accidents seen in the table above, such as collisions, fires, sinks, grounding, and other events that can be life-threatening and property. Four important factors when an accident occurs are ship type, cause of accident, accident time and place of accident.

The FSA approach on this APBS for existing ships are Tanker, Container, Passenger ship, Tug Boat, Barge and other types of vessels. The causes of accidents are caused by the human factor itself, technical factors, and natural factors. For the occurrence of accidents occurred in the area of West Sailing Channel Surabaya and time of accident one day 24 hours from 00:00 to 24:00.

This analysis makes a large amount of data being shared, the most important thing in the data collection of sea accidents. In the process of determining the accident scenario, all accidents must be recorded or collected and each accident is a different accident scenario.

The use of the FSA approach method is to improve the safety of maritime depending on accurate statistical data. After considering the accident factor, each accident is defined in several scenarios. In the data there are 122 total accidents appear in Surabaya's West Sailing Station in the period. The most frequent accidents are ship collisions followed by ship fire and others. Table 7 shows the risk type of accident. 
Table 7: Risk Type of Accident

\begin{tabular}{|c|c|c|c|c|c|c|c|c|}
\hline & \multicolumn{4}{|c|}{ Most Likely Consequence } & \multicolumn{4}{|c|}{$\begin{array}{c}\text { Worst Credible } \\
\text { Consequence }\end{array}$} \\
\hline Event & 氶 & 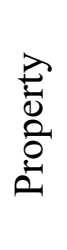 & 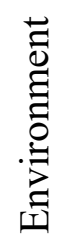 & 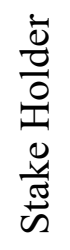 & 啡 & $\begin{array}{l}\text { Dें } \\
0 \\
0 \\
0 \\
0\end{array}$ & 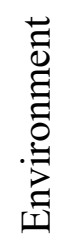 & 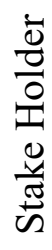 \\
\hline Collision & 6 & 6 & 0 & 6 & 9 & 9 & 6 & 8 \\
\hline Sink & 3 & 6 & 0 & 3 & 7 & 7 & 0 & 6 \\
\hline Fire & 6 & 6 & 0 & 3 & 8 & 8 & 6 & 6 \\
\hline Other & 6 & 6 & 0 & 6 & 8 & 8 & 7 & 7 \\
\hline Grounding & 3 & 6 & 0 & 3 & 7 & 7 & 0 & 6 \\
\hline
\end{tabular}

To rank the highest risk need to give scoring to the value that occurs in humans, the environment, etc. so each type of accident can be in a proportional order. Giving a value of 0.6 is quite rational if we place human safety as a top priority. It would be irrational if the weighted value for humans is given as high as 0.7 and above because it means very little material value, which in reality should be considered. Table 8 shows safety weighted value.

Table 8: Safety Weighted Value

\begin{tabular}{|l|c|}
\hline \multicolumn{2}{|c|}{ Scoring } \\
\hline Human & 0,6 \\
\hline Property & 0,15 \\
\hline Environment & 0,15 \\
\hline Stake Holder & 0,1 \\
\hline
\end{tabular}

The risk type accident in APBS results gained after weighting as shown in Table 9. The giving of the rank is subjective because so far there is no count or standard value to explain how important human life compared with property, ownership or the other things, nevertheless there are some considerations of why to take that value.

The results show that the crash on the channel is the highest-risk event followed by the ship fires, others that can be life-threatening and property and other. However more important is how lowered the high risk that happens to be an acceptable risk value. Sink has a low value, but has a high enough risk. The ship's accidents are caused by various outcomes that charge a cost. The literature on this cost is very complex to determine a realistic cost based on its value. The biggest risk of accidents in APBS is ship fire. From 2010 to 2016 there are 27 burnt ship fires which are caused by several factors. 
Table 9: Safety Weighted Value

\begin{tabular}{|c|c|c|c|c|c|c|c|c|c|c|}
\hline & \multicolumn{4}{|c|}{$\begin{array}{l}\text { Most Likely } \\
\text { Consequ en ce }\end{array}$} & \multicolumn{4}{|c|}{$\begin{array}{l}\text { Worst Credible } \\
\text { Consequ en ce }\end{array}$} & \multirow[b]{2}{*}{ 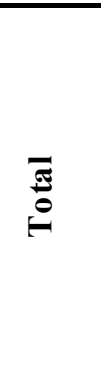 } & \multirow[b]{2}{*}{ : } \\
\hline Event & $\stackrel{\Xi}{\Xi}$ & : & 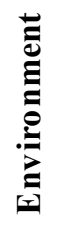 & $\begin{array}{l}\frac{\overline{0}}{0} \\
\frac{0}{0} \\
\frac{0}{0} \\
\frac{\pi}{0}\end{array}$ & $\underset{\Xi}{\Xi}$ & 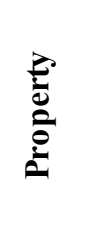 & 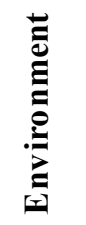 & $\begin{array}{l}\frac{\dot{0}}{0} \\
\frac{0}{0} \\
\frac{0}{10} \\
\frac{\pi}{0}\end{array}$ & & \\
\hline Collision & 3,6 & 0,9 & 0 & 0,6 & 5,4 & 1,35 & 0,9 & 0,8 & 13,35 & 1 \\
\hline Sink & 1,8 & 0,9 & 0 & 0,3 & 4,2 & 1,05 & 0 & 0,6 & 10,35 & 4 \\
\hline Fire & 3,6 & 0,9 & 0 & 0,3 & 4,8 & 1,2 & 0,9 & 0,6 & 13,10 & 2 \\
\hline Other & 3,8 & 0,9 & 0 & 0,6 & 4,8 & 1,2 & 1,05 & 0,7 & 12,85 & 3 \\
\hline Grounding & 1,8 & 0,9 & 0 & 0,3 & 4,2 & 1,05 & 0 & 0,7 & 8,85 & 5 \\
\hline
\end{tabular}

From the type of five accidents, there are several factors that affect the occurrence of collisions, sink, fire, grounding, and others that can be life-threatening and treasure. Among the human, technical and natural factor, the human factors are the highest in the occurrence of accidents in APBS. Figure 2 shows the accident causes from 2013 to 2016 there were 39 of them caused by human factor. More than $60 \%$ are caused by humans and the remaining $30 \%$ and $10 \%$ are caused by technical and natural factors. Human factors consist of qualification, experience, and safety. Of the three factors, experience is an important factor that is the experience of the ship's captains to pass the APBS.

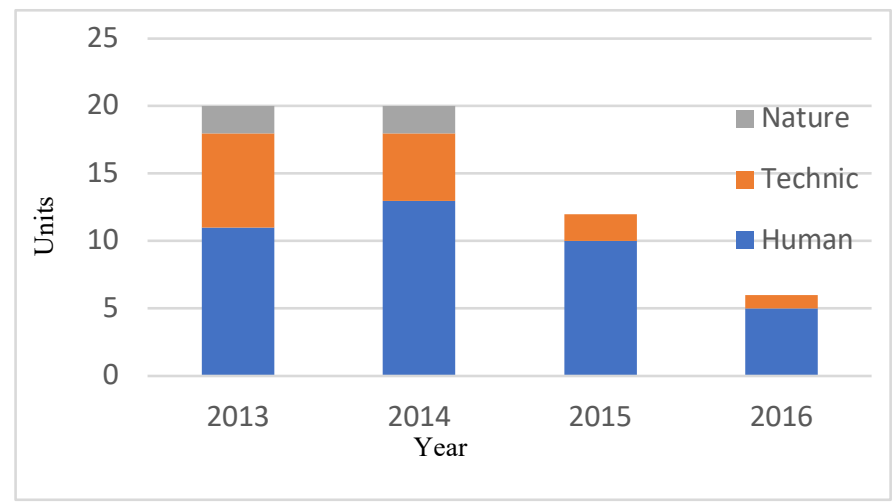

Figure 2: Accident Causes

The technical factor consists of navigation, management and the ship itself, from the three factors the navigation factors are caused by technical constraints on the navigational system, while the ship's factors are caused by the age of the vessel and its linkage and factor management due to the owner and management of the vessel from maintenance management and operation management. Natural factors are caused by bad weather factors. The weather that generates wind, currents, big waves that lead to unexpected events.

Related to determining the selection of risk control, all are crucial accident factors that have been analysed and the level of risk established to prevent hazard. Therefor the risk reduction is very important associated with the level of accidents if sorted in the highest such as collision, ship fires, sink, grounding and others. The five types of accidents there are several ways to reduce the risk of 
such accidents, such as seafarer training and certification, routine patrol and installation of channel sign, human rescue training, tight port area, tightening of sailing permit and law enforcement. Selection of risk Control, such as ship collision can be minimized by tightening the port area. Ship fires can be minimized by training and certifying seafarers. Others that can be life-threatening and property can be minimized by routine patrols around the harbour or cruise line. The sinking vessels can be minimized by procuring a sailing permit so that it will still sail on a specified channel or area.

Cost and benefit assessment is the process of evaluating the costs and benefits of risk reduction measures. In this step, if the benefits of risk reduction have a higher value than the cost, it may be selectable and applicable. If ships are monitored more cautiously, the cause of crews can be prevented and the risk of accidents can be reduced.

With the correct handling the risk accident can be reduce or In this case, any risk from the cause of accidents in the West Surabaya Shipping Channel can be reduced by $10-40 \%$. Because the risk is reduced, the cost of countermeasures can be reduced. And the benefits of accident risk reduction can save expenses by $10-50 \%$.

The value $10-50 \%$ get by formula (1) which has been calculated. Based on the formula that the risk accident has been reduction because of the RCO. The cost to be incurred for each type of accident is reduced due to RCO. To calculate the ICAR is required Cost of risk control $(\Delta C)$ Economic benefits of the application of risk control $(\Delta \mathrm{B})$. Cost control is derived from calculating the needs of each type of risk control. Each type of control has the required different cost depending on the need Tightening control of sail has the highest cost and tightened port area has the lowest cost. Benefit cost is obtained by calculating the benefits of the existence of the cost of risk control.

ICAR is obtained by entering the calculated cost into equation (1) by entering the value of the decreased risk. With appropriate risk control, the cost of mitigation can be reduced. The cost of countermeasure the collision is reduced by $10 \%$, to grounding $50 \%$, fire $40 \%$, and sink $50 \%$, others that can endanger life and property $50 \%$.

Recommendations for decision making with implementation of FSA can reduce the risk of accidents in APBS. However, the risks cannot be completely eliminated, at least minimally. In this risk assessment, the highest risk reaches 9 and it can be defined as a very high risk and includes intolerable. Risk control techniques should be applied continuously and should be continuously improved to ensure safety while sailing in APBS. The following is a list of recommendations:

- Monitoring marine traffic is more cautious. This recommendation is useful to reduce the occurrence of the risk of collision.

- Limitation of marine traffic in bad weather conditions. Especially in times of bad weather, this option helps reduce accident risk factors caused by natural factors such as weather.

- Monitoring of places at risk of accidents.

- The emergency teams must be in the most dangerous position of the area and the team must have a fire-fighter.

- The ship registry for travel: vessel with the high risk should be recorded. Based on this information, ships that have a high level at an inaccessible level should be monitored more carefully.

- Ship speed condition: based to COLREG 72, the ship speed must be satisfied the APBS each condition and area. Therefore, it is necessary to prepare the risk that will occur and emergency planning.

- In order to maintain the level of risk, it is necessary to have the relevant monitoring, procedures, and rules applied to APBS and port users by the safety committee.

- Removal sinking vessels and other obstacles contained in the APBS channel for shipping navigation safety. 
- There is information about navigation on the APBS channel, including tides, currents, weather information, and electronic navigation chart for the APBS users.

\section{Conclusion}

Today, the great majority of world trade takes place by sea. In this context, the APBS has a very important role. Tanjung Perak Port is one of the busiest main ports in Indonesia. Currently the shipping route to Tanjung Perak Port has two paths namely the Surabaya western access channel (APBS) and the Surabaya Eastern access channel (APTS). The marine traffic is increasing annually has caused marine safety problems. From the results of the analysis conducted are as follows:

1. Based on data of ship visits at Tanjung Perak Port, in the period of 2011 to 2016 there was an increase of GT vessels averaging $2.05 \%$, while ship units decreased by an average of $2.33 \%$.

2. The number of ship accident events in APBS before and after the revitalization is quite high. This is seen from the total incidence of accidents from 2010 to 2016 as many as 122 cases. Before the revitalization of 2010 until 2014 there were 100 accidents or an average of 20 cases of accidents per year. After the revitalization of 2015 to 2016 there are 22 cases or an average of 11 cases per year. So there is a decrease in accident cases between before and after the revitalization is about $100 \%$.

3. Of the five types of accidents occurring in the APBS after the revitalization is the impact of 8 cases or $36.5 \%$, ship fire 7 cases or $31.8 \%$, sink and grounding each of 3 cases or $13.6 \%$ and others as much as 1 case or $4.5 \%$.

4. The number of ship accident events APBS is quite high. This is seen from the total incidence of accidents during from 2010 to 2016 as many as 122 cases. After the calculation, the five types of accidents that occurred in the four types of accidents that have a high risk of ship collision, followed by fire, others and ship sink.

5. The causes of accidents before the revitalization from 2013 until the year 2014 as many as 40 cases of accidents, human factors are as many as 24 cases or by $60 \%$, the cause of technical factor accidents as many as 12 cases or by $30 \%$ and for natural factors are as many as 4 cases or by $10 \%$. Meanwhile, after revitalization from 2015 until 2016, there were 18 cases, with human factor causing 15 cases or $83.3 \%$, technical causes as many as 3 cases or $16.7 \%$ and natural factors as the cause of the accident did not exist.

6. The cause of accidents for human factors is a major factor in the occurrence of accidents both before and after revitalization. Human factors as the cause of accidents experienced a significant increase of $20 \%$ from before and after revitalization, while for other factors of accidents, such as technical factors and natural factors decreased significantly.

7. When the risk of accidents can be reduced. In this case, any risk from the cause of accidents in APBS can be reduced by $10-40 \%$ and the benefits of accident risk reduction can save expenses by $30-50 \%$.

\section{References}

[1] IMO (2002). Guidelines for FSA for use in the IMO Rule, Making Process, MSC/ Circ.1023 \& MEPC/ Circ.392, London.

[2] IMO (2004). A Guide to Risk Assessment in Ship Operations, IACS, London.

[3] Ömer Faruk Görçüna, Selmin.Z Burak (2015). Formal Safety Assessment for Ship Traffic in the Istanbul Straits. 11th International Strategic Management Conference 2015. Procedia - Social and Behavioral Sciences 207 (2015) 252 261.

[4] Report of Kajian Resiko Pelayaran di APBS (Alur Pelayaran Barat Surabaya/Selat Madura) Didasarkan Pada Data Pergerakan Lalu Lintas Kapal, Badan Litbang Perhubungan, Kementerian Perhubungan, 2017 (in Indonesian). 